\title{
Improvement in Cr Nanoparticle Content in Ni-Cr Film by Co-deposition with Combined Surfactant HPB and CTAB
}

\author{
Li-Juan Qin ${ }^{1}$ - Yuan-Chao Huang ${ }^{1,2}$
}

Received: 11 February 2017/Revised: 12 March 2017/Published online: 21 April 2017

(C) The Chinese Society for Metals and Springer-Verlag Berlin Heidelberg 2017

\begin{abstract}
The effects of single surfactant hexadecylpyridinium bromide (HPB) and cetyltrimethylammonium bromide (CTAB) and the combination of HPB and CTAB on the $\mathrm{Cr}$ nanoparticle content in the $\mathrm{Ni}-\mathrm{Cr}$ film prepared by codeposition were investigated. Single HPB/CTAB addition inhibited the oxidation and amorphous transformation of the $\mathrm{Cr}$ nanoparticles in the plating bath and effectively stabilized the $\mathrm{Cr}$ nanoparticles content at approximately 10 mass\% as a function of time. Moreover, the combination of HPB and CTAB formed a cylindrical micelle structure on the $\mathrm{Cr}$ nanoparticle surface, which prompted the formation of a layer of $\mathrm{NiCr}_{2} \mathrm{O}_{4}$. As a result, the $\mathrm{Cr}$ nanoparticle content increased sharply to 20 mass $\%$.
\end{abstract}

KEY WORDS: Co-deposition; Ni-Cr film; Cr nanoparticle content; HPB; CTAB

\section{Introduction}

Co-deposition of nanosized particles into a metal matrix has been used to successfully fabricate $\mathrm{Ni}-\mathrm{SiC}[1,2]$, Ni-

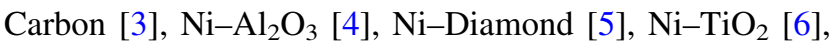
$\mathrm{Ni}-\mathrm{Cr}[7,8]$ and $\mathrm{Ni}-\mathrm{Cr}-\mathrm{Al}[9,10]$ nanocomposite films. These nanocomposites exhibit enhanced wear resistance, thermal stability and corrosion resistance compared to the pure metallic materials. In particular, the $\mathrm{Ni}-\mathrm{Cr}[7,8]$ nanocomposite shows a superior resistance to high-temperature oxidation and hot corrosion due to the rapid formation of compact, slow-growing and thermodynamically stable $\mathrm{Cr}_{2} \mathrm{O}_{3}$ oxide. To guarantee excellent performance at

Available online at http://link.springer.com/journal/40195.

Li-Juan Qin

qinlijuan345@163.com

1 Laboratory for Corrosion and Protection, Institute of Metal Research, Chinese Academy of Sciences, Shenyang 110016, China

2 College of Material Science and Engineering, University of Science and Technology of China, Hefei 230026, China high temperatures, the content of the $\mathrm{Cr}$ nanoparticles in the film must exceed the critical value of 9.6 mass\% [8] to prompt the formation of the protective $\mathrm{Cr}_{2} \mathrm{O}_{3}$ layer and ensure the consumption of $\mathrm{Cr}$ during the long oxidation period.

However, many studies have proved that it is usually difficult for the nanosized particle to be co-deposited and that the content of the nanoparticles in the film is very limited compared to that of the micro-sized particle [11-14]. Numerous methods have been used to improve the content of the nanoparticles, such as adjusting the electrodeposition parameters $[12,15]$, changing the sediment methods [15, 16] and adding inorganic metal ions [5, 17] or organic surfactants [14, 18-21]. Optimization of the codeposition process parameters such as the current density, particle concentration, bath composition, agitator speed gave rise to particle content fluctuation in a relatively small range. Although sediment co-deposition (SCD) where the cathode is horizontally set in the bath could attain a higher particle content in the film, the higher content could be obtained for only one side of the sample. The use of surfactants, especially cationic surfactants such as hexadecylpyridinium bromide (HPB) [18, 21, 22], 
cetyltrimethylammonium bromide (CTAB) [14] and an azobenzene group surfactant (AZATB) [19], are recognized as the most effective way to improve the content of the incorporated particles. The most remarkable characteristic of the surfactant is its participation in the solidliquid interface with the hydrophilic head and the hydrophobic hydrocarbon chain [23]. In the co-deposition process, previous studies have shown that the aggregation of the nanoparticles can be decreased in a plating bath with surfactant [14]. Additionally, the charge of the particles can be changed to positive [21,22] with the adsorption of a cationic surfactant that could promote electrophoretic migration of the particles toward the cathode. For example, the $\mathrm{SiC}(250 \mathrm{~nm})$ content in the nickel matrix was improved to $11.5 \mathrm{vol} \%$ by the addition of CTAB [14]. The content of $\mathrm{Al}_{2} \mathrm{O}_{3}(80 \mathrm{~nm})$ in the nickel matrix was improved to 14.7 vol\% with the addition of HPB [18]. The synergistic behavior of binary surfactant also is exploited to reduce the total amount of surfactant used or improve the quality of film. For example, the content of $\mathrm{Al}_{2} \mathrm{O}_{3}$ $(150 \mathrm{~nm})$ in nickel matrix was improved by the addition of a combination of anionic SDS and cationic HPB [21]. The anionic surfactant SDS is used to decrease the pore defects of the as-deposited film. In this paper, instead of a combination of an anionic and a cationic surfactant the combination of two cationic HPB and CTAB was chosen to reduce the total amount and form the specific micelles which are a barrier of the ions adsorbed on the $\mathrm{Cr}$ nanoparticles surface in plating bath.

In this study, the optimum parameters of the $\mathrm{Cr}$ content in the Ni-Cr film were studied. Additionally, the effects of single $\mathrm{HPB} / \mathrm{CTAB}$ and combined $\mathrm{HPB}$ and $\mathrm{CTAB}$ on the surface modification of the $\mathrm{Cr}$ nanoparticles (average size of $40 \mathrm{~nm}$ ) and its content in the nickel matrix were studied.

\section{Experimental}

$\mathrm{Ni}-\mathrm{Cr}$ nanocomposite films were deposited from a nickel sulfate solution. The components of bath and the parameters of co-deposition are shown in Table 1. A certain content of the nanoparticles of pure $\mathrm{Cr}$ with an average size of $40 \mathrm{~nm}$ was added into the bath with ultrasonic stirring before the co-deposition. A reciprocating perforated plate was added in the bath during the co-deposition to maintain the suspension of the nanoparticles. Pure nickel (99.9\%) with dimensions of $15 \times 10 \times 2 \mathrm{~mm}$ was chosen as the substrate after being abraded using an 800 -grit $\mathrm{SiC}$ paper. The bath temperature was $30^{\circ} \mathrm{C}$, and the $\mathrm{pH}$ was 5.5-6.0. Various concentrations of the $\mathrm{Cr}$ nanoparticles in the electrolyte and the direct current (DC) density were applied, as shown in Table 1. Additionally, the relationship between the $\mathrm{Cr}$ nanoparticles after different soaking times
Table 1 Parameters of the $\mathrm{Ni}-\mathrm{Cr}$ co-deposition

\begin{tabular}{ll}
\hline Bath composition & $\mathrm{NiSO}_{4} \cdot 6 \mathrm{H}_{2} \mathrm{O}: 50-100 \mathrm{~g} / \mathrm{L}$ \\
& $\mathrm{NaCl}: 10 \mathrm{~g} / \mathrm{L}$ \\
& $\mathrm{C}_{6} \mathrm{H}_{5} \mathrm{NaO}_{7} \cdot 2 \mathrm{H}_{2} \mathrm{O}: 110 \mathrm{~g} / \mathrm{L}$ \\
& $\mathrm{HBO}_{3}: 20 \mathrm{~g} / \mathrm{L}$ \\
Cr nanoparticles concentration & $50-300 \mathrm{~g} / \mathrm{L}$ \\
Current density (DC) & $0.5-5 \mathrm{~A} / \mathrm{dm}^{2}$ \\
Plating time & $1 \mathrm{~h}$ \\
pH & $5.5-6$ \\
Temperature & $30{ }^{\circ} \mathrm{C}$ \\
\hline
\end{tabular}

in bath $(0,30,60,90$ and 120 days) and $\mathrm{Cr}$ content in $\mathrm{Ni}-\mathrm{Cr}$ film was also investigated. Then, single surfactant HPB $(250 \mathrm{mg} / \mathrm{L})$, CTAB $(200 \mathrm{mg} / \mathrm{L})$ and a combined HPB $(250 \mathrm{mg} / \mathrm{L})$ and CTAB $(200 \mathrm{mg} / \mathrm{L})$ in analytical grade were added into bath to investigate their effect. All the codeposition was carried within $1 \mathrm{~h}$. The average thickness of these films is $15 \mu \mathrm{m}$.

The weight fraction of $\mathrm{Cr}$ nanoparticles in the $\mathrm{Ni}-\mathrm{Cr}$ nanocomposite film was measured by energy-dispersive X-ray spectroscopy (EDX) connected to a Philips XL30FEG scanning electron microscope (SEM). The microstructure of the $\mathrm{Cr}$ nanoparticles, especially the oxide phase, after different soaking durations in the plating bath was observed by transmission electron microscopy (TEM). Two major steps were used to prepare the samples for TEM. The given $\mathrm{Cr}$ nanoparticles were fully dispersed into alcohol using ultrasonic agitation, and then, a copper mesh was placed into the dispersive $\mathrm{Cr}$ nanoparticles alcohol bath. Finally, the samples were dried in the air to stand by service. The composition of the oxide phase of the $\mathrm{Cr}$ nanoparticles was tested by X-ray photoelectron spectroscopy (XPS), the samples for which were taken from the plating solution after drying prior to the measurement.

\section{Results and Discussion}

\subsection{Co-deposition Parameter Optimization}

To investigate the effect of the $\mathrm{Cr}$ nanoparticles concentration on the their content in the nickel matrix without surfactant, various concentrations of the $\mathrm{Cr}$ nanoparticles ranging from 50 to $300 \mathrm{~g} / \mathrm{L}$ were added to the plating bath at the fixed current density of $2 \mathrm{~A} / \mathrm{dm}^{2}$ and the $\mathrm{NiSO}_{4}$ concentration of $50 \mathrm{~g} / \mathrm{L}$. The result is shown in Fig. 1a. As the concentration of the $\mathrm{Cr}$ nanoparticles increases, the $\mathrm{Cr}$ content gradually increases to approximately 9.7 mass\%. However, when the $\mathrm{Cr}$ nanoparticles concentration was as 

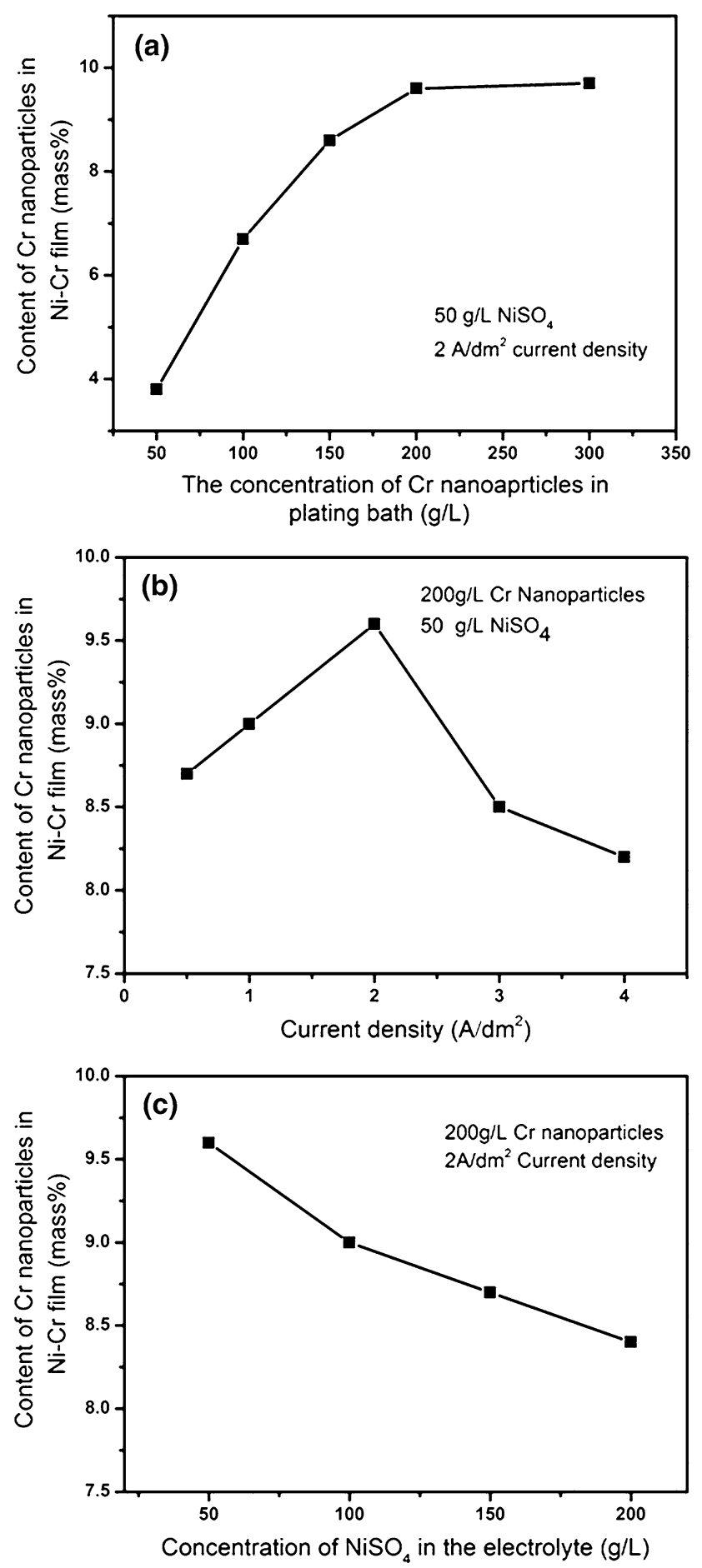

Fig. 1 Relationship between $\mathrm{Cr}$ content in mass\% in $\mathrm{Ni}-\mathrm{Cr}$ film and a $\mathrm{Cr}$ nanoparticle concentrations in bath, $\mathbf{b}$ current density, $\mathbf{c} \mathrm{NiSO}_{4}$ concentration in bath without surfactant

high as $300 \mathrm{~g} / \mathrm{L}$, no change was observed compared to the $\mathrm{Cr}$ concentration of $200 \mathrm{~g} / \mathrm{L}$. This variation in $\mathrm{Cr}$ content with the $\mathrm{Cr}$ concentration in the plating bath was similar to the Langmuir isotherm adsorption phenomenon [17, 24]. A higher concentration of $\mathrm{Cr}$ nanoparticles could lead to more
Cr nanoparticles being transported to and adsorbing onto the surface of the cathode, so more $\mathrm{Cr}$ nanoparticles would be engulfed by the reduced Ni. However, when the concentration of the $\mathrm{Cr}$ nanoparticles was higher than $200 \mathrm{~g} / \mathrm{L}$, the adsorption of the $\mathrm{Cr}$ particles on the cathode surface reached the saturation with no more sites to accept more $\mathrm{Cr}$ nanoparticles. Therefore, no further increase in $\mathrm{Cr}$ content was observed.

The current density varying from 0.5 to $5 \mathrm{~A} / \mathrm{dm}^{2}$ was applied for the conditions of the $\mathrm{Cr}$ nanoparticles concentration of $200 \mathrm{~g} / \mathrm{L}$ and $\mathrm{NiSO}_{4}$ concentration of $50 \mathrm{~g} / \mathrm{L}$ in the electrolyte without surfactant in order to investigate the relationship between the $\mathrm{Cr}$ nanoparticle content in the $\mathrm{Ni}-$ $\mathrm{Cr}$ film and the current density. As shown in Fig. 1b, as the current density increases from 0.5 to $5 \mathrm{~A} / \mathrm{dm}^{2}$, the $\mathrm{Cr}$ content increases from 8.7 mass $\%$ to the peak of 9.6 mass\% when the current density reached $2 \mathrm{~A} / \mathrm{dm}^{2}$ and then decreases to 8.2 mass $\%$ at $5 \mathrm{~A} / \mathrm{dm}^{2}$. This effect can be related to the efficiency of the nickel reduction. As the current increases from 0.5 to $2 \mathrm{~A} / \mathrm{dm}^{2}$, the nickel reduction became more rapid, incorporating more particles in the $\mathrm{Ni}$ matrix. However, when the current density was higher than $2 \mathrm{~A} / \mathrm{dm}^{2}$, a significant amount of hydrogen was reduced, and $\mathrm{H}_{2}$ separated out; this hindered the adsorption of the nanoparticles to the cathode and resulted in a decrease in the nanoparticles' content [25].

$\mathrm{NiSO}_{4}$ concentration in the plating bath was another important factor influencing the content of the co-deposited particles in the nickel matrix. $\mathrm{Ni}-\mathrm{Cr}$ nanocomposite film was prepared under different baths containing different $\mathrm{NiSO}_{4}$ concentrations ranging from 50 to $200 \mathrm{~g} /$ $\mathrm{L}$ for the conditions of the Cr nanoparticles' concentration of $200 \mathrm{~g} / \mathrm{L}$ and current density of $2 \mathrm{~A} / \mathrm{dm}^{2}$ without surfactant. Figure 1c shows the relationship between the $\mathrm{Cr}$ content in the $\mathrm{Ni}-\mathrm{Cr}$ film and $\mathrm{NiSO}_{4}$ concentration. The Cr content declined slightly from 9.6 to 7.5 mass\% as the $\mathrm{NiSO}_{4}$ concentration increased from 50 to $200 \mathrm{~g} / \mathrm{L}$. The agglomeration of the $\mathrm{Cr}$ nanoparticles is decreased at the lower $\mathrm{NiSO}_{4}$ concentration due to the lower strength of ionic interactions between the nanoparticles in the bath. Good dispersion of the nanoparticles can improve the content of the co-deposited nanoparticles by facilitating the movement of the nanoparticles in the plating bath [26]. The content of $\mathrm{Al}_{2} \mathrm{O}_{3}$ nanoparticles $(80 \mathrm{~nm})$ in $\mathrm{Ni}-$ $\mathrm{Al}_{2} \mathrm{O}_{3}$ film also decreased with increasing the concentration of $\mathrm{Ni}^{2+}$ in the bath that has been reported by Kuo et al. [27].

Most importantly, the maximum $\mathrm{Cr}$ nanoparticles' content (approximately 9.7 mass\%) in the $\mathrm{Ni}-\mathrm{Cr}$ film can be achieved at the $\mathrm{Cr}$ nanoparticle concentration of $200 \mathrm{~g} /$ $\mathrm{L}$, current density of $2 \mathrm{~A} / \mathrm{dm}^{2}$ and $\mathrm{NiSO}_{4}$ concentration in the plating bath of $50 \mathrm{~g} / \mathrm{L}$. 


\subsection{Oxidation of $\mathrm{Cr}$ Nanoparticles in Plating Bath}

Upon the repeated use of the $\mathrm{Ni}-\mathrm{Cr}$ bath to fabricate the $\mathrm{Ni}-\mathrm{Cr}$ nanocomposite film, $\mathrm{Cr}$ nanoparticles could not avoid being soaked for a long time in the plating bath. As the time of being soaked in the bath increased, $\mathrm{Cr}$ nanoparticles were slightly oxidized, which may further impact the co-deposited particles in the $\mathrm{Ni}$ matrix. According to the Celis model [28], the chemical composition and structure of the $\mathrm{Cr}$ nanoparticles' surface in the electrolyte determined the adsorption of the surrounding ions and further influenced the process of the particle being engulfed by the nickel on the cathode surface. $\mathrm{Cr}$ nanoparticles subjected to different soaking times ranging from 0 to 120 days in the plating bath were used to investigate the relationship between the $\mathrm{Cr}$ content and the time of soaking with plating at the optimum co-deposition parameters. As shown in Fig. 2, as the Cr nanoparticles' soaking time increased, the $\mathrm{Cr}$ content in the $\mathrm{Ni}-\mathrm{Cr}$ film decreased. In the 0-30-day range, the $\mathrm{Cr}$ content decreased sharply from 9.6 to 6.0 mass\%. In the subsequent 90 days (i.e., after being soaked for 120 days), the $\mathrm{Cr}$ content further decreased gradually to 4.1 mass $\%$.

TEM was used to observe the morphology of the $\mathrm{Cr}$ nanoparticles after the different soaking times in the bath. As shown in Fig. 3, Cr nanoparticles that were soaked for 1,30 and 120 days were gradually oxidized and transformed into amorphous state. The fresh (1 day) $\mathrm{Cr}$ nanoparticle shown in Fig. 1a exhibits a core-shell structure $[29,30]$. The core consists of body-centered structure (bcc) $\mathrm{Cr}$ metal. The shell was the epitaxial passive facecentered cubic structured (fcc) oxide $\mathrm{Cr}_{2} \mathrm{O}_{3}$ film (approximately $2.5 \mathrm{~nm}$ thick) that was formed due to the oxidation during the fabrication process. However, the oxide shell became thicker with increasing soaking time. At 30 days,

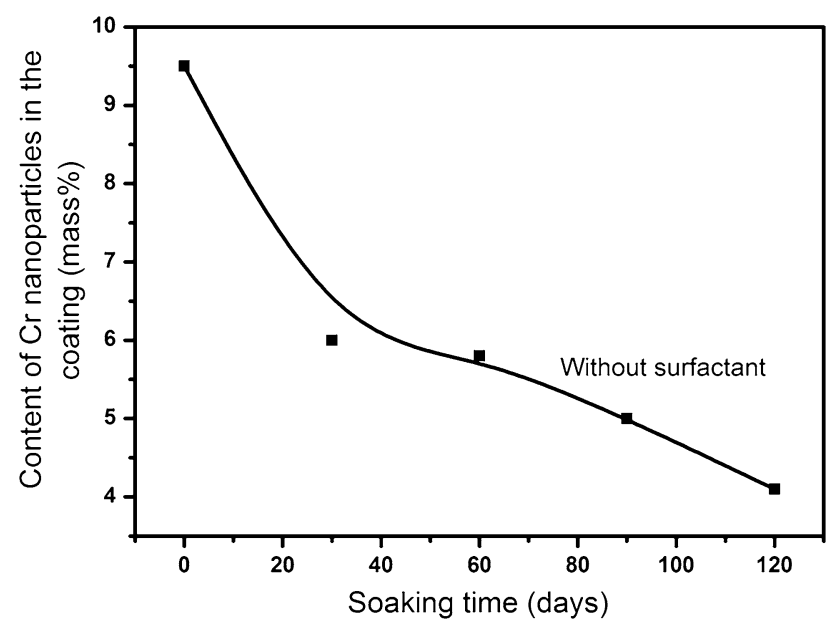

Fig. 2 Relationship between $\mathrm{Cr}$ content in mass \% in $\mathrm{Ni}-\mathrm{Cr}$ film and soaking time without surfactant the thickness of the oxide shell grew to $3 \mathrm{~nm}$ and was approximately $5.6 \mathrm{~nm}$ on the 120th day, as shown in Fig. 3b, c. It is important to note that the structure of this
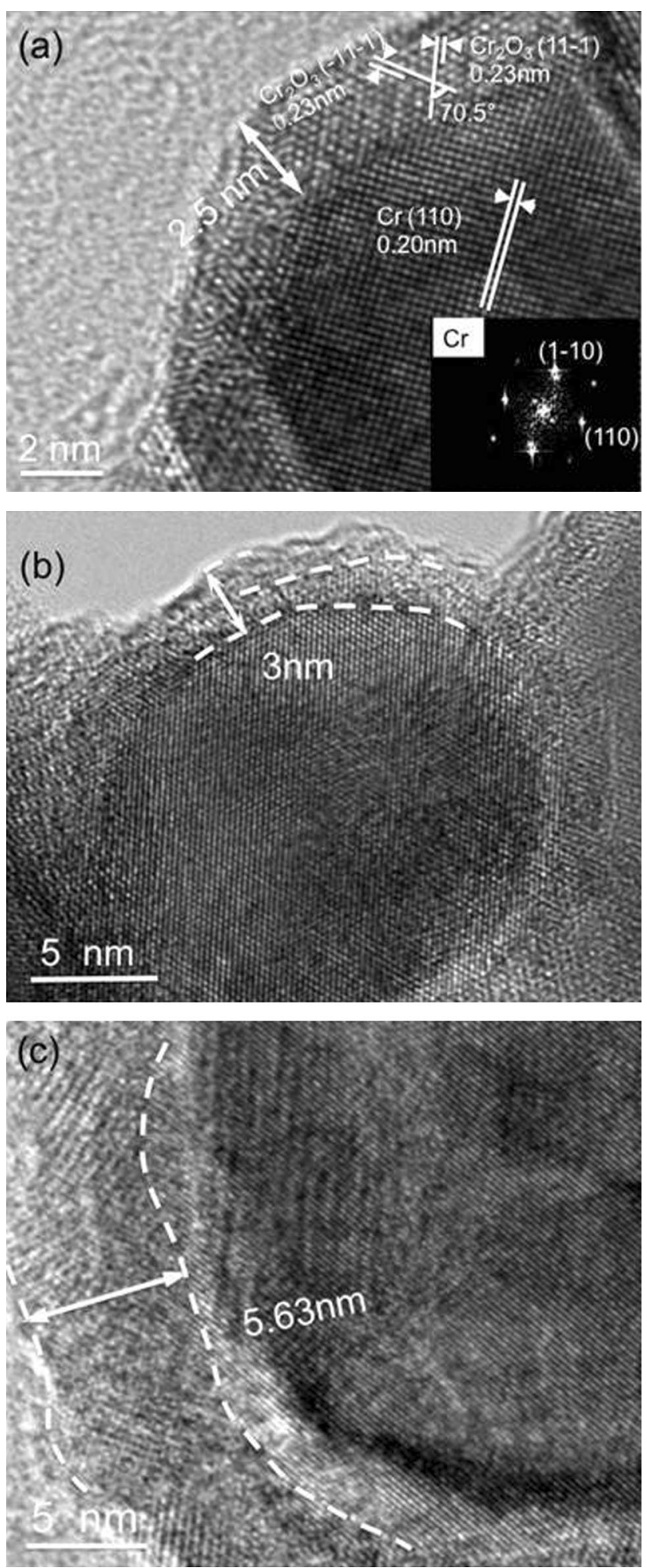

Fig. 3 Morphologies of $\mathrm{Cr}$ nanoparticle after soaking for a 1 day, b 30 days, c 120 days 
shell did not preserve the crystalline state and apparently changed into an amorphous state.

Moreover, Fig. 4 shows the XPS results for the fresh (1 day) $\mathrm{Cr}$ nanoparticle and the $\mathrm{Cr}$ nanoparticle after soaking for 120 days. The XPS survey spectra of these two kinds of $\mathrm{Cr}$ nanoparticles contained $\mathrm{C} 1 s, \mathrm{O} 1 s$ and $\mathrm{Cr}$ $2 p$ lines in Fig. 4a. The peak fitting of the $\mathrm{Cr} 2 p 3 / 2$ spectra
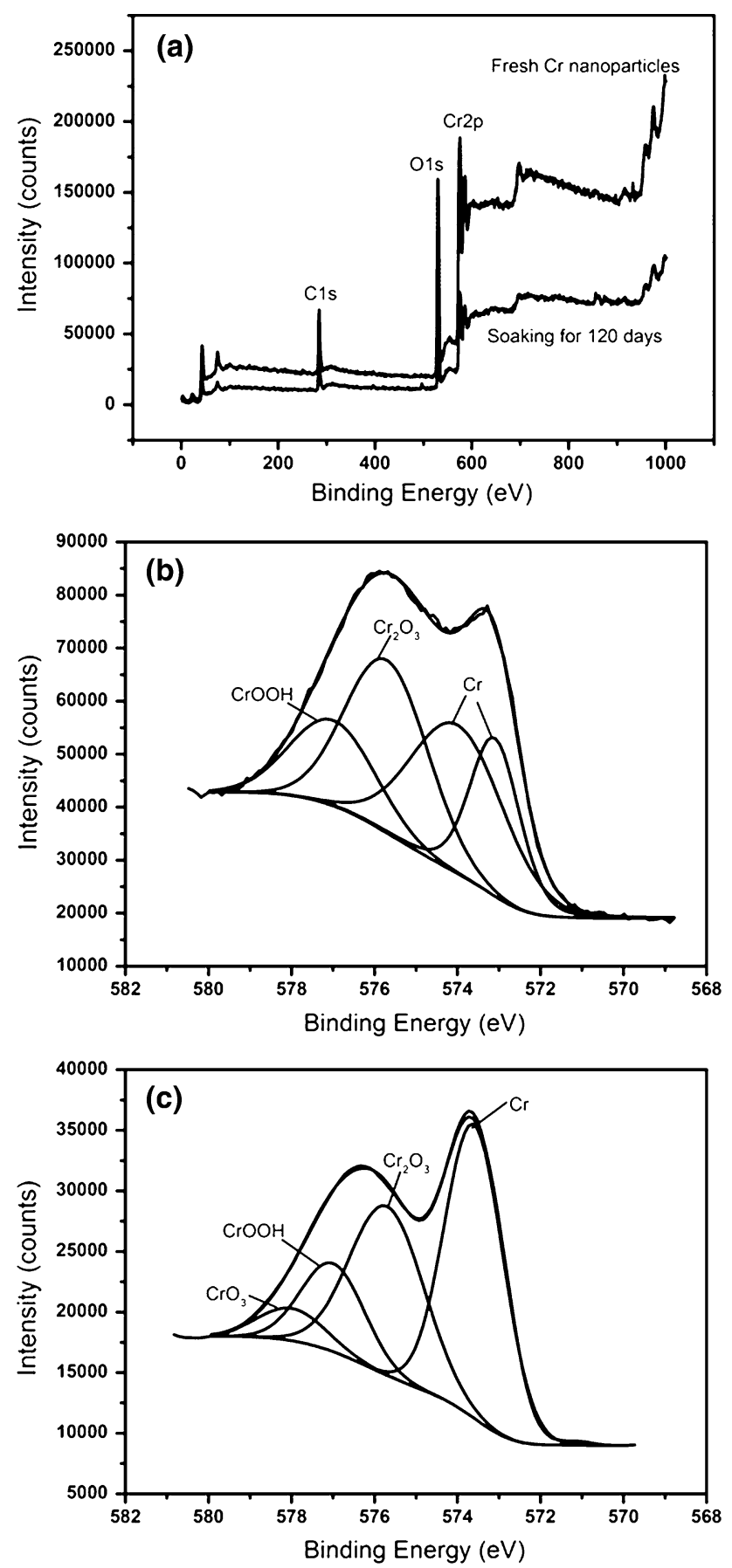

Fig. 4 XPS spectra of $\mathrm{Cr}$ nanoparticle after soaking for 1 day and 120 days a survey spectrum, the $\mathrm{Cr} 2 p 3 / 2$ spectra of $\mathrm{Cr}$ nanoparticle after soaking for $\mathbf{b} 1$ day and $\mathbf{c} 120$ days of the different $\mathrm{Cr}$ nanoparticles was conducted using the commercial XPSPEAK41 software to examine the composition of the oxide shell. Figure $4 \mathrm{~b}$ shows the peak fitting results for the fresh $\mathrm{Cr}$ nanoparticle, where $\mathrm{Cr}, \mathrm{Cr}_{2} \mathrm{O}_{3}$ and $\mathrm{CrOOH}$ [31] were observed at $573 \mathrm{eV}(\mathrm{Cr})$ and $574 \mathrm{eV}$ $(\mathrm{Cr}), 575.7 \mathrm{eV}\left(\mathrm{Cr}_{2} \mathrm{O}_{3}\right)$ and $577 \mathrm{eV}(\mathrm{CrOOH})$ as presented in Table 2. Thus, the shell of the fresh $\mathrm{Cr}$ nanoparticles consists predominantly of $\mathrm{Cr}_{2} \mathrm{O}_{3}$. The formation of $\mathrm{CrOOH}$ was due to the $\mathrm{H}_{2} \mathrm{O}$ adsorbed during the sample preparation process. However, after soaking for 120 days $\mathrm{CrO}_{3}$ was observed [31] (578 eV in Table 2), as were the peaks of $\mathrm{Cr}$, $\mathrm{Cr}_{2} \mathrm{O}_{3}$ and $\mathrm{CrOOH}$ in Fig. 4c. The existence of $\mathrm{CrO}_{3}$ indicates that some $\mathrm{Cr}^{3+}$ were oxidized to $\mathrm{Cr}^{6+}$ bonding with $\mathrm{O}^{2-}$ to form $\mathrm{CrO}_{3}$ in the electrolyte.

In conclusion, as the soaking time was extended from 1 day to 120 days, the oxide shell of the $\mathrm{Cr}$ nanoparticles grew and gradually changed from a crystalline state to an amorphous state, accompanied by the oxidation of some of the $\mathrm{Cr}_{2} \mathrm{O}_{3}$ shell into $\mathrm{CrO}_{3}$. The decrease in the $\mathrm{Cr}$ content in the $\mathrm{Ni}-\mathrm{Cr}$ film could be attributed to the amorphous transformation of the Cr nanoparticles' oxide shell. Celis [28] proposed that the particles on the cathode were incorporated by the reduction in the surrounding ion layer. Moreover, the amount and type of ion adsorbed on the particles were determined by the surface state of the particles. Compared to crystalline state, there is no existence of the defects, such as dislocation, grain boundary, because their atomic arrangements are disorderly, which is the same reason of why amorphous coating has excellent corrosion resistance. These defects (steps, kinks, edges and corners) are known as the active sites with high energy levels that have been proved by other authors [32, 33], where adsorption and reactivity are improved. So, in the co-deposition of $\mathrm{Ni}-\mathrm{Cr}$, the amorphous oxide shell on the surface of the Cr nanoparticles significantly reduced the amount of active sites for ion adsorption compared to the crystalline state. Therefore, less $\mathrm{Ni}$ ion absorption around the $\mathrm{Cr}$ nanoparticles resulted in decreasing incorporation of the $\mathrm{Cr}$ nanoparticles in the $\mathrm{Ni}$ matrix.

\subsection{Effect of Single Surfactant HPB/CTAB}

Single surfactant HPB $(250 \mathrm{mg} / \mathrm{L}) / \mathrm{CTAB}(200 \mathrm{mg} / \mathrm{L})$ was added into the bath. Similarly, for the optimal co-deposition parameters, the relationship between the content of the $\mathrm{Cr}$ nanoparticles in the $\mathrm{Ni}-\mathrm{Cr}$ film and soaking time was investigated, as shown in Fig. 5. Compared to the case without the surfactant, the addition of HPB or CTAB makes the content of $\mathrm{Cr}$ gradually increase from 2.3 mass\% on the 1 st day to approximately 10 mass $\%$ on the 90th day. Furthermore, as the soaking time increased to 120 days, no obvious decreasing trend was observed, making $\mathrm{Cr}$ content stable at approximately 10 mass $\%$. Generally, a surfactant 
Table 2 Binding energies for peak fitting of $\mathrm{Cr} 2 p 3 / 2$ spectra

\begin{tabular}{|c|c|c|c|c|c|c|}
\hline Type of nanoparticle & $\mathrm{Cr}$ & $\mathrm{Cr}_{2} \mathrm{O}_{3}$ & $\mathrm{CrOOH}$ & $\mathrm{CrO}_{3}$ & $\mathrm{C}-\mathrm{Cr}-\mathrm{H}$ & $\mathrm{NiCr}_{2} \mathrm{O}_{4}$ \\
\hline Fresh Cr & $573 / 574$ & 575.7 & 577 & - & - & - \\
\hline Cr soaking for 120 days & 574 & 575.7 & 577 & 578 & - & - \\
\hline $\mathrm{Cr}$ with $\mathrm{HPB}$ & $573 / 574$ & 575.7 & 577 & - & - & - \\
\hline Cr with CTAB & $573 / 574$ & 575.7 & 577 & - & - & - \\
\hline Cr with HPB and CTAB & 574 & 575.7 & 577 & - & 574.6 & 575.2 \\
\hline
\end{tabular}

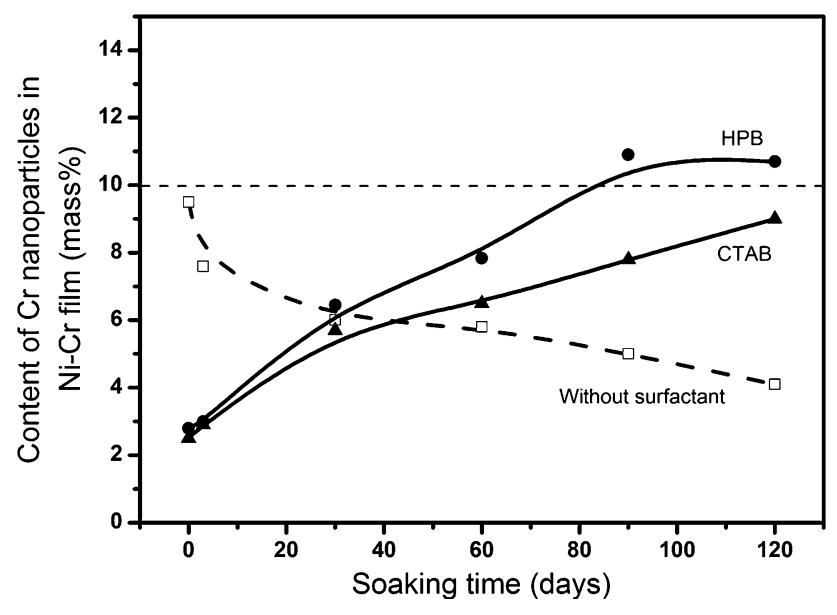

Fig. 5 Relationship between $\mathrm{Cr}$ content in mass\% in $\mathrm{Ni}-\mathrm{Cr}$ film and soaking time with the addition of HPB/CTAB

molecule has two different ends: hydrophilic head and hydrophobic chain. In solution, HPB or CTAB molecules may have been adsorbed on the surface of the particles with their cationic charged hydrophilic head to the surface and the hydrophobic chain outward to the solution or vice versa. Additionally, according to Chen et al. [34], the adsorption process of cationic surfactant onto a metal oxide surface is a function of time. For the first several days after adding HPB/CTAB into the plating bath, the surfactant molecules are adsorbed onto the $\mathrm{Cr}$ nanoparticles surface through dipole-dipole bonds [34]; this adsorption is not very strong. Most surfactant molecules could reversibly desorb and became free in the electrolyte. During the plating process, free surfactants would like to be adsorbed onto the cathode surface, highly decreasing the number of sites of the nickel reduction and blocked the $\mathrm{Cr}$ nanoparticles with the surfactant molecules close to the cathode. This leads to the decrease from 9.7 to 2.3 mass $\%$ on the first day. It would take several days or even months for the surfactant molecules and ions (i.e., $\mathrm{Ni}^{2+}$ ) in the electrolyte to rearrange on the particle surface and bind to the surface more strongly via Coulombic (ionic) bonds rather than the dipole-dipole bonds [34]. At this time, most surfactant molecules are adsorbed on the $\mathrm{Cr}$ nanoparticles, and only trace amounts were still free. Therefore, on the 90th day, most HPB/CTAB molecules would not further influence the nickel reduction, and the $\mathrm{Cr}$ content remained stable at 10.2 and 8.9 mass\% for the additions of HPB and CTAB, respectively. Most importantly, the addition of the single surfactant HPB/CTAB stabilized the $\mathrm{Cr}$ content at approximately 9 mass\% and no decreasing trend was observed despite the long soaking time in the bath.

Single surfactant HPB/CTAB added in the bath tended to adsorb on the surface of the $\mathrm{Cr}$ nanoparticles and selfassemble forming monolayers, bilayers, spherical or rodlike micelles [35-37], when the concentration of the surfactant is near or above the critical micelle concentration (CMC). In this work, the HPB and CTAB concentrations were near CMC. Therefore, a full monolayer was formed on the particle surface that occupied the active sites on the surface. The full monolayer of the surfactant blocked the adsorption of $\mathrm{O}_{2}$ in the bath and inhibited the oxidation and amorphous transformation of the $\mathrm{Cr}$ nanoparticles. TEM results of the $\mathrm{Cr}$ nanoparticles soaked for 120 days with the addition of HPB and CTAB presented in Fig. 6 show that the thickness of the oxide shell of the Cr nanoparticles did not change and was obviously still approximately $2.5 \mathrm{~nm}$. The lattice of the oxide shell of the Cr nanoparticles is still crystalline. Furthermore, $\mathrm{Cr} 2 p 3 / 2$ spectra of two kinds of $\mathrm{Cr}$ nanoparticles with $\mathrm{HPB} / \mathrm{CTAB}$ were fitted and analyzed as shown in Fig. 7. $\mathrm{Cr}, \mathrm{Cr}_{2} \mathrm{O}_{3}$ and $\mathrm{CrOOH}$ peaks [31] are observed that are same as the peaks for the fresh nanoparticles (Table 2). It was obvious that $\mathrm{Cr}$ nanoparticles had not been oxidized with HPB/CTAB, despite being soaked for 120 days in the plating bath.

Furthermore, the addition of HPB increased the $\mathrm{Cr}$ nanoparticle content to 10.2 mass $\%$ at 90 days, which was slightly higher than ordinary 9.7 mass $\%$, and the addition of CTAB stabilized the $\mathrm{Cr}$ content at 8.9 mass\%. Thus, the addition of HPB to the bath not only inhibited the oxidation of the $\mathrm{Cr}$ nanoparticles but may also improve the net positive charge of the particles. However, the addition of CTAB may not improve the net positive charge of the $\mathrm{Cr}$ nanoparticles. Instead, the remaining free CTAB impacted the nickel reduction slightly and decreased the $\mathrm{Cr}$ content. 

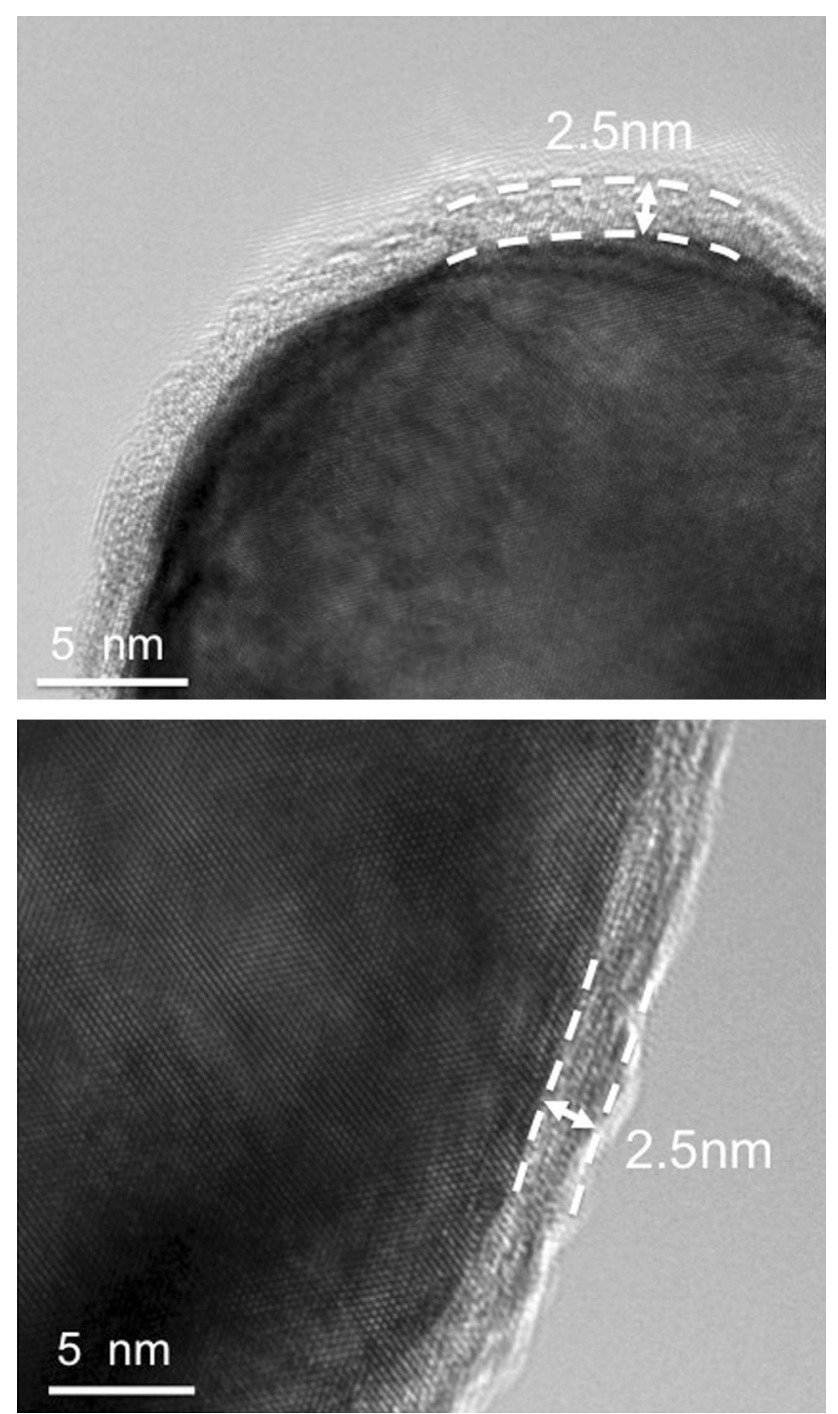

Fig. 6 Morphologies of $\mathrm{Cr}$ nanoparticle after 120 days of soaking in the bath with the addition of a HPB, b CTAB

\subsection{Effect of Combined HPB and CTAB}

Combined HPB (250 mg/L) and CTAB (200 mg/L) was added to the bath to study the effect of combined HPB and $\mathrm{CTAB}$ on the $\mathrm{Cr}$ content in the $\mathrm{Ni}-\mathrm{Cr}$ film. Figure 8 shows that the $\mathrm{Cr}$ mass\% gradually increased from approximately 2. to 7.9 mass\% with the extension of the soaking time from 1 day to 60 days, and the $\mathrm{Cr}$ mass\% increased dramatically to 19.8 mass\% at 90 days.

The morphology of the $\mathrm{Cr}$ nanoparticles soaked for 120 days with the addition of the combination of HPB and CTAB is shown in Fig. 9. It shows that the oxide shell of the $\mathrm{Cr}$ nanoparticle was still approximately $2.5 \mathrm{~nm}$ thick and was in the crystalline state. No obvious oxidation and amorphous transformation occurred. However, there are four atomic layers on the particle surface, for which the lattice was different from the oxide shell of the
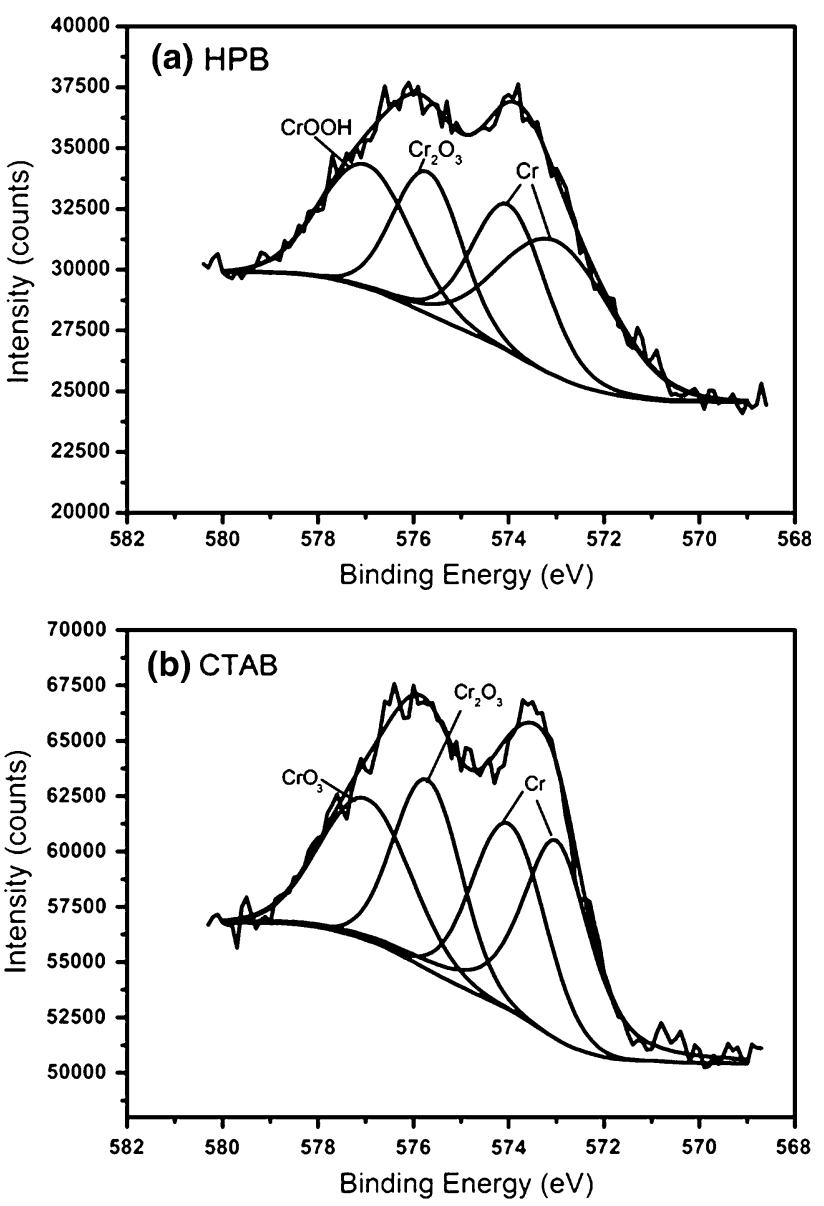

Fig. 7 XPS spectra of $\mathrm{Cr} 2 p 3 / 2$ of $\mathrm{Cr}$ nanoparticle after 120 days of soaking in the bath with the addition of $\mathbf{a}$ HPB, $\mathbf{b}$ CTAB

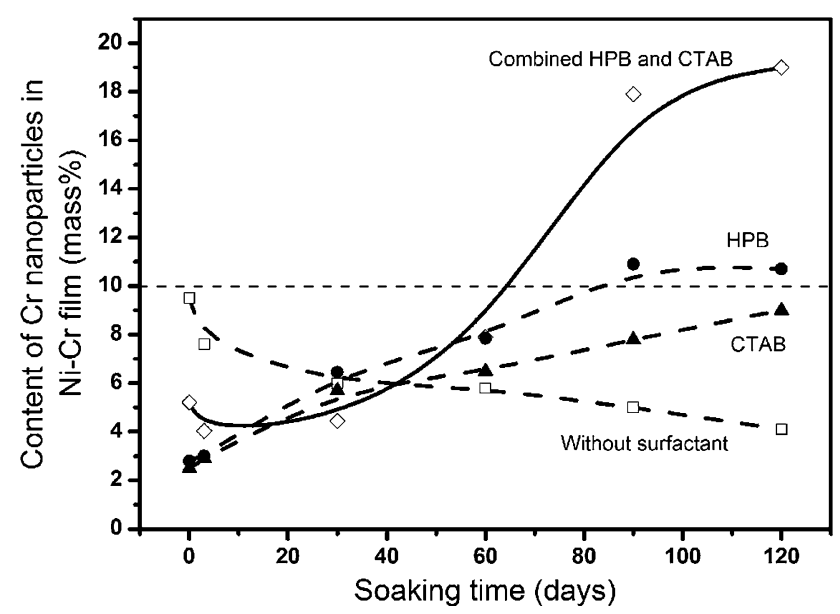

Fig. 8 The relationship between $\mathrm{Cr}$ content in mass\% in $\mathrm{Ni}-\mathrm{Cr}$ film and soaking time with the addition of combined HPB and CTAB

nanoparticles described above. In addition, the aggregation of the surfactant at the height of approximately $4 \mathrm{~nm}$ was present on the surface of the $\mathrm{Cr}$ particle. Cr nanoparticles were further examined in detail by XPS. The XPS survey spectrum shown in Fig. 10a contains $\mathrm{C} 1 s, \mathrm{O} 1 s, \mathrm{Cr} 2 p$ and 


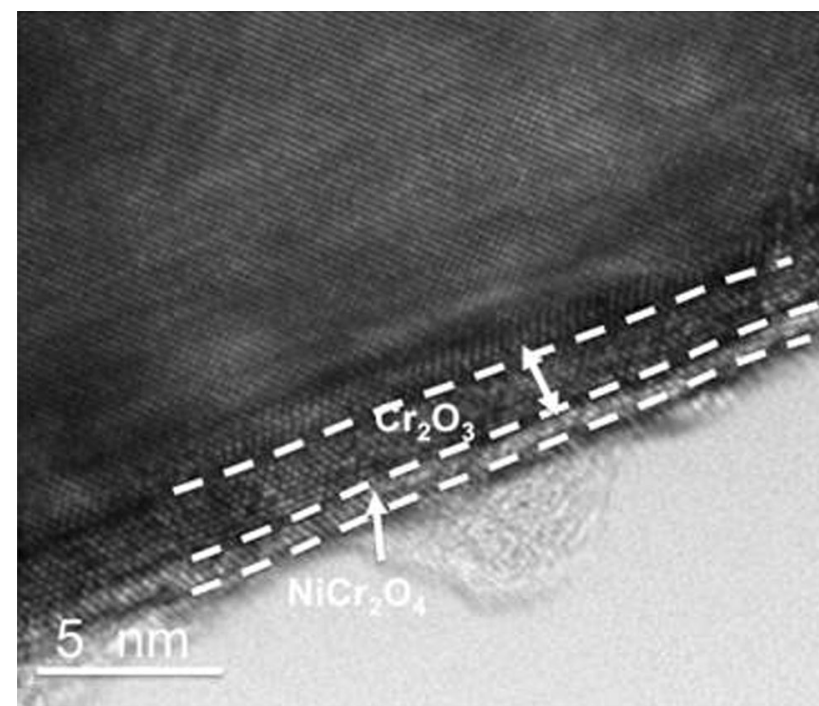

Fig. 9 Morphology of $\mathrm{Cr}$ nanoparticle after 120 days of soaking in the bath with the addition of combined HPB and CTAB

Ni $2 p$ lines. An extra Ni $2 p$ line is present compared to the spectrum of the fresh nanoparticles and nanoparticles with the addition of either HPB or CTAB. The peak fitting for the $\mathrm{Cr} 2 p 3 / 2$ and $\mathrm{Ni} 2 p 3 / 2$ spectra is presented in Fig. 10b, c. $\mathrm{Cr}, \mathrm{Cr}_{2} \mathrm{O}_{3}, \mathrm{CrOOH}, \mathrm{NiCr}_{2} \mathrm{O}_{4}$ [38] and $\mathrm{C}-\mathrm{Cr}-\mathrm{H}$ [39] is observed at binding energies of $573 \mathrm{eV}(\mathrm{Cr})$, $575.7 \mathrm{eV}\left(\mathrm{Cr}_{2} \mathrm{O}_{3}\right), \quad 577 \mathrm{eV}(\mathrm{CrOOH}), \quad 575.2 \mathrm{eV}\left(\mathrm{NiCr}_{2} \mathrm{O}_{4}\right)$ and $574.6 \mathrm{eV}(\mathrm{C}-\mathrm{Cr}-\mathrm{H})$, in Fig. $10 \mathrm{~b}$ and Table 2. The formation of $\mathrm{C}-\mathrm{Cr}-\mathrm{H}$ is caused by the chemical adsorption of the hydrocarbon chains of the surfactant. $\mathrm{NiCr}_{2} \mathrm{O}_{4}$ and $\mathrm{NiO}$ are also observed at $853.8 \mathrm{eV}\left(\mathrm{NiCr}_{2} \mathrm{O}_{4}\right)$ and $855 \mathrm{eV}$ $(\mathrm{NiO})$ with the core and satellite line structure [40] in the Ni 2p3/2 spectra shown in Fig. 10c. Combined with the morphology of the $\mathrm{Cr}$ nanoparticle, the $\mathrm{Cr}_{2} \mathrm{O}_{3}$ phase of the $\mathrm{Cr}$ nanoparticles was not further oxidized, but a thin layer of $\mathrm{NiCr}_{2} \mathrm{O}_{4}$ and $\mathrm{NiO}$ was formed on the particle surface.

According to the XPS and TEM results, the combination of HPB and CTAB not only protected the oxidation of the $\mathrm{Cr}$ nanoparticles but also improved the formation of $\mathrm{NiCr}_{2} \mathrm{O}_{4}$ and $\mathrm{NiO}$ on their surfaces. Generally, a combination of two kinds of cationic surfactants is applied to lower the CMC in the solution [41]. Compared to the addition of either HPB or CTAB only, the CMC of the combination of these surfactants is lower than a single surfactant [42]. As a result, the self-assembling shape of their mixture may have transformed from monolayers to cylinders as a function of the time in the solution $[33,43]$. The sharp increase in the content of the $\mathrm{Cr}$ nanoparticles in the $\mathrm{Ni}-\mathrm{Cr}$ film to approximately 20 mass \% could also be attributed to the cylindrical micelles structure. On the one hand, the cylinder micelles structure is considered to provide a higher surface charge of the particles through the absorption of a large amount of the surfactant molecules, thereby promoting
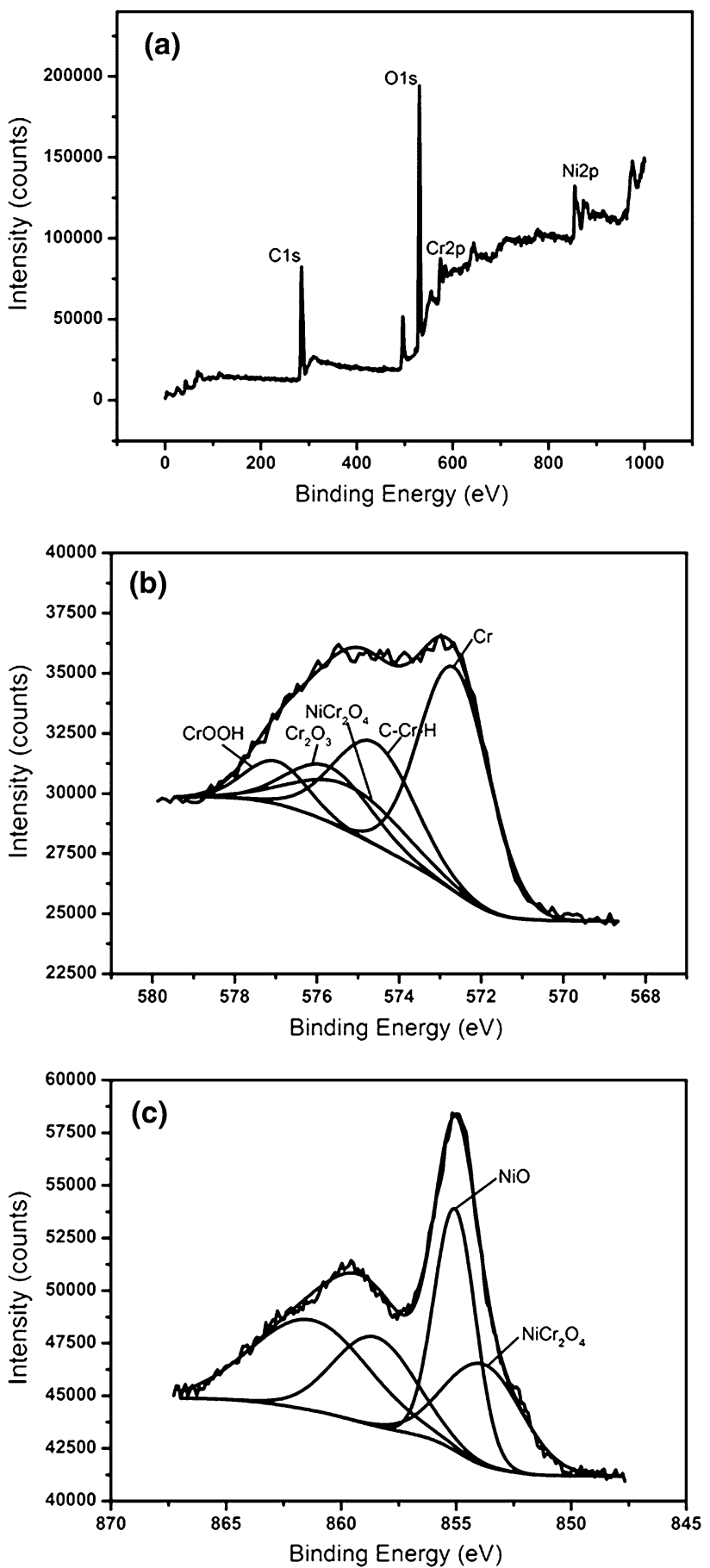

Fig. 10 a XPS spectra, b Cr $2 p 3 / 2$ spectra, c Ni2p3/2 spectra obtained from $\mathrm{Cr}$ nanoparticle 120 days of soaking in the bath with the addition of combined HPB and CTAB

electrophoretic migration of the suspended particles. On the other hand, Ducker and Wanless [43] found that CTAB formed stable cylindrical micelles in the $\mathrm{KBr}$ solution at two times of CMC. The formation of cylindrical micelles greatly slows the adsorption of $\mathrm{H}^{+}$on the surface, whereas the rate of $\mathrm{K}^{+}$adsorption is not noticeably affected. This illustrates that the adsorbed film of the surfactant on the 
surface acted as a barrier and was ion selective. In our study, the cylindrical micelles of mixed HPB and CTAB on the $\mathrm{Cr}$ particle surface could be an obstacle for the absorption of $\mathrm{H}^{+}$, but some of $\mathrm{Ni}^{2+}$ traversed cylindrical micelles and directly adsorbed on the active sites. The selective adsorption of $\mathrm{Ni}^{2+}$ and not $\mathrm{H}^{+}$could significantly improve the chance of the $\mathrm{Cr}$ nanoparticles being incorporated in the nickel matrix. Importantly, the formation of $\mathrm{NiCr}_{2} \mathrm{O}_{4}$ and $\mathrm{NiO}$ leads to the exposure of more nickel atoms on the surface of the $\mathrm{Cr}$ nanoparticles. These nickel atoms could act as the nucleation sites of nickel to enable easier nickel reduction. The formation of $\mathrm{NiCr}_{2} \mathrm{O}_{4}$ and $\mathrm{NiO}$ could be attributed to the chemical adsorption of the surfactant. The chemical adsorption of the hydrocarbon chains of the surfactant resulted in the formation of $\mathrm{C}-\mathrm{Cr}-\mathrm{H}$ and the electrons transferred to the oxide phase of the $\mathrm{Cr}$ nanoparticles [44-46]. Absorbed $\mathrm{Ni}^{2+}$ may get electrons and change to $\mathrm{Ni}$ and then react with $\mathrm{Cr}_{2} \mathrm{O}_{3}$ to change to $\mathrm{NiO}$. Some regions of $\mathrm{NiO}$ further reacted with $\mathrm{Cr}_{2} \mathrm{O}_{3}$ to form $\mathrm{NiCr}_{2} \mathrm{O}_{4}$.

\section{Conclusions}

1. 9.7 mass\% $\mathrm{Cr}$ nanoparticle content can be achieved in the conditions of $200 \mathrm{~g} / \mathrm{L} \mathrm{Cr}$ nanoparticle content in the bath, $2 \mathrm{~A} / \mathrm{dm}^{2}$ current density and $50 \mathrm{~g} / \mathrm{L} \mathrm{NiSO}_{4}$ concentration in the plating bath.

2. Cr nanoparticles were oxidized, and the oxide shell was in an amorphous state as the soaking time of the $\mathrm{Cr}$ nanoparticles in plating bath was increased. This leads to the $\mathrm{Cr}$ nanoparticle content sharply decreasing to 4.1 mass $\%$.

3. Single surfactant HPB and CTAB can be adsorbed on the surface of the $\mathrm{Cr}$ nanoparticles and inhibit their oxidation, eventually stabilizing the $\mathrm{Cr}$ nanoparticle content at approximately 10 mass $\%$.

4. A combination of HPB and CTAB not only inhibited the oxidation of the $\mathrm{Cr}$ nanoparticles but also promoted the formation of a thin layer of $\mathrm{NiCr}_{2} \mathrm{O}_{4}$ on the $\mathrm{Cr}$ nanoparticle surface. This highly improved the $\mathrm{Cr}$ nanoparticles content to approximately 20 mass $\%$.

\section{References}

[1] M.R. Vaezi, S.K. Sadrnezhaad, L. Nikzad, Colloids Surf. A 315, 1 (2008)

[2] L. Benea, P.L. Bonora, A. Borello, S. Martelli, Wear 249, 10 (2001)

[3] X.H. Chen, F.Q. Cheng, S.L. Li, L.P. Zhou, D.Y. Li, Surf. Coat. Technol. 155, 2 (2002)

[4] R.R. Oberle, M.R. Scanlon, R.C. Cammarata, P.C. Searson, Appl. Phys. Lett. 66, 1 (1995)
[5] L.P. Wang, Y. Gao, H.W. Liu, Q. Xue, T. Xu, Surf. Coat. Technol. 191, 1 (2005)

[6] D. Thiemig, A. Bund, Surf. Coat. Technol. 202, 13 (2008)

[7] Y. Zhang, X. Peng, F. Wang, Mater. Lett. 58, 6 (2004)

[8] X. Peng, Nanoscale 2, 2 (2010)

[9] X. Yang, X. Peng, C. Xu, F. Wang, J. Electrochem. Soc. 156, 5 (2009)

[10] X. Yang, X. Peng, F. Wang, Scripta Mater. 56, 10 (2007)

[11] S.K. Kim, H.J. Yoo, Surf. Coat. Technol. 108, 564-569 (1998)

[12] G. Maurin, A. Lavanant, J. Appl. Electrochem. 25, 12 (1995)

[13] B.S. Xu, H. Wang, S. Dong, B. Jiang, W. Tu, Electrochem. Commun. 7, 6 (2005)

[14] M.D. Ger, Mater. Chem. Phys. 87, 1 (2004)

[15] H. Gül, M. Uysal, H. Akbulut, A. Alp, Surf. Coat. Technol. 258, 1202-1211 (2014)

[16] H. Liu, W. Chen, Surf. Coat. Technol. 191, 2 (2005)

[17] S.C. Wang, W.C.J. Wei, Mater. Chem. Phys. 78, 3 (2003)

[18] H. Gül, F. Kılıç, S. Aslan, Wear 267, 5 (2009)

[19] N.K. Shrestha, M. Masuko, T. Saji, Wear 254, 5 (2003)

[20] N.K. Shrestha, T. Takebe, T. Saji, Diam. Relat. Mater. 15, 10 (2006)

[21] S.W. Jiang, L. Yang, J.N. Pang, H. Lin, Z.Q. Wang, Surf. Coat. Technol. 286, 197-205 (2016)

[22] L. Chen, L. Wang, Z. Zeng, J. Zhang, Mater. Sci. Eng. A 434, 1 (2006)

[23] S. Manne, H.E. Gaub, Science. 270(5241), 1480 (1995)

[24] C.T.J. Low, R.G.A. Wills, F.C. Walsh, Surf. Coat. Technol. 201, 1 (2006)

[25] S.W. Banovic, K. Barmak, A.R. Marder, J. Mater. Sci. 34, 13 (1999)

[26] J.L. Anderson, F. Rauh, A. Morales, J. Phys. Chem. 82, 5 (1978)

[27] S.L. Kuo, Y.C. Chen, M.D. Ger, W.H. Hwu, Mater. Chem. Phys. 86, 1 (2004)

[28] J.P. Celis, J.R. Roos, C. Buelens, J. Electrochem. Soc. 134(6), 1402-1408 (1987)

[29] K. Kimoto, I. Nishida, Jpn. J. Appl. Phys. 6, 9 (1967)

[30] K. Tamura, Y. Kimura, H. Suzuki, O. Kido, T. Sato, T. Tanigaki, M. Kurumada, Y. Saito, C. Kaito, Jpn. J. Appl. Phys. 42, 12R (2003)

[31] B. Stypula, J. Stoch, Corros. Sci. 36, 12 (1994)

[32] T.W. Hansen, J.B. Wagner, P.L. Hansen, S. Dahl, H. Topsøe, C.J.H. Jacobsen, Science 294, 5546 (2001)

[33] L.C. Gontard, L.-Y. Chang, C.J.D. Hetherington, A.I. Kirkland, D. Ozkaya, R.E. Dunin-Borkowski, Angew. Chem. 119, 20 (2007)

[34] Y.L. Chen, S. Chen, C. Frank, J. Israelachvili, J. Colloid Interface Sci. 153, 1 (1992)

[35] R. Atkin, V.S.J. Craig, E.J. Wanless, S. Biggs, Adv. Colloid Interface Sci. 103, 3 (2003)

[36] S. Garoff, H.W. Deckman, J.H. Dunsmuir, M.S. Alvarez, J.M. Bloch, J. Phys. 47, 4 (1986)

[37] S. Manne, H.E. Gaub, Science 270, 5241 (1995)

[38] M.C. Biesinger, B.P. Payne, A.P. Grosvenor, L.W. Lau, A.R. Gerson, R.S.C. Smart, Appl. Surf. Sci. 257, 7 (2011)

[39] M.P. Seah, in Practical Surface Analysis by Auger and X-ray Photoelectron Spectroscopy, ed. by Martin P. Seah, D. Briggs (Wiley, New York, 1983

[40] N.S. McIntyre, M.G. Cook, Anal. Chem. 47, 13 (1975)

[41] S.P. Moulik, M.E. Haque, P.K. Jana, A.R. Das, J. Phys. Chem. 100, 2 (1996)

[42] M. Bergström, J.C. Eriksson, Langmuir 16, 18 (2000)

[43] W.A. Ducker, E.J. Wanless, Langmuir 15, 1 (1999)

[44] P.B. Weisz, J. Chem. Phys. 21, 9 (1953)

[45] E.L. Muetterties, J.R. Bleeke, E.J. Wucherer, T. Albright, Chem. Rev. 82, 5 (1982)

[46] J.L. Whitten, H. Yang, Surf. Sci. Rep. 24, 3-4 (1996) 